\title{
Sistem Diagnosis Penyakit Jantung Koroner Dengan Menggunakan Algoritma C4.5 Berbasis Website (Studi Kasus: RSUD Dr. Soedarso Pontianak)
}

\author{
Siti Riska Julianti Ihnur Alham ${ }^{1}$; Efy Yosrita ${ }^{2}$; Rizqia Cahyaningtyas ${ }^{3}$ \\ 1, 2, 3 Institut Teknologi PLN \\ ${ }^{1}$ si1731151@itpln.ac.id \\ 2 efy.yosrita@itpln.ac.id \\ ${ }^{3}$ rizqia@itpln.ac.id
}

\begin{abstract}
Heart disease is also called coronary heart disease. Saat this method used by the hospital to give clinical decisions made based on the science and experience of doctors in treating coronary heart diseasepatients. by utilizing patient data that has been stored in the database, then created a pattern of determining coronary heart disease with intelligent computational techniques so that uncertainty of diagnosis results can be avoided. The authors conducted a study to diagnosecoronary heart disease using the decision tree method with the C4.5 algorithm. The advantages of this algorithm are easily understood, and can be described in the form of a decision tree based on the risk factors experienced by the patient. Risk factors include age, gender, hereditary factors, systolic blood pressure, diastolic blood pressure, total cholesterol levels, HDL (High Density Lipoprotein) levels, LDL (Low Density Lipoprotein) levels and triglyceride levels. Based on testing using confusion matrix with accuracy tingat parameter obtained value of $94.4 \%$
\end{abstract}

Keywords: heart coroner, $C 4.5$, decision tree

\begin{abstract}
ABSTRAK
Penyakit jantung disebut juga dengan penyakit jantung koroner. Saat ini metode yang digunakan oleh pihak rumah sakit untuk memberi keputusan klinis dibuat berdasarkan ilmu pengetahuan dan pengalaman dari dokter dalam menangani pasien-pasien penyakit jantung koroner. dengan memanfaatkan data-data pasien yang telah tersimpan dalam basis data, kemudian dibuat suatu pola penentuan penyakit jantung koroner dengan teknik komputasi cerdas sehingga ketidak pastian hasil diagnosis dapat dihindari. Penulis melakukan penelitian untuk mendiagnosis penyakit jantung koroner menggunakan metode decision tree dengan algoritma C4.5. Kelebihan dari algoritma ini adalah dapat dipahami dengan mudah, dan dapat digambarkan dalam bentuk pohon keputusan berdasarkan faktor resiko yang dialami pasien. Faktor resikonya antara lain umur, jenis kelamin, faktor keturunan, tekanan darah sistolik, tekanan darah diastolik, kadar kolesterol total, kadar HDL (High Density Lipoprotein), kadar LDL (Low Density Lipoprotein) dan kadar trigliserida.Berdasarkan pengujian menggunakan confusion matrix dengan parameter tingat akurasi diperoleh nilai sebesar $94,4 \%$
\end{abstract}

Kata kunci: jantung coroner, C4.5, pohon keputusan 


\section{PENDAHULUAN}

Penyakit jantung koroner (PJK) adalah penyakit yang disebabkan adanya plak yang menumpuk di dalam arteri koroner yang mensuplai oksigen ke otot jantung. Menurut statistik dunia, ada 9,4 juta kematian setiap tahun[1][2][3] yang disebabkan oleh penyakit kardiovaskuler dan 45\% kematian tersebut disebabkan oleh penyakit jantung coroner, diperkirakan angka tersebut akan meningkat hingga 23,3 juta pada tahun 2030.[4]Penyakit jantung koroner (PJK) adalah penyakit jantung akibat penyempitan atau penyumbatan pembuluh nadi koroner. Penyempitan atau penyumbatan ini dapat menghentikan aliran darah ke otot jantung yang sering ditandai dengan rasa nyeri. Dalam kondisi lebih parah kemampuan jantung dalam memompa darah dapat hilang

Diagnosis penyakit jantung koroner dapat dilakukan menggunakan metode decision tree dengan algoritma C4.5. Kelebihan dari algoritma ini adalah dapat dipahami dengan mudah, dan dapat digambarkan dalam bentuk pohon keputusan berdasarkan faktor resiko yang dialami pasien. Faktor resikonya antara lain umur, jenis kelamin, faktor keturunan, tekanan darah sistolik, tekanan darah diastolik, kadar kolesterol total, kadar HDL (High Density Lipoprotein), kadar LDL (Low Density Lipoprotein) dan kadar trigliserid[5][6]. Penelitian ini menggunakan proses data mining. Data mining adalah sebuah proses, sehingga dalam melakukan prosesnya harus sesuai prosedur yaitu proses CRISP-DM (Cross-Industry Standard Process for Data Mining) [7][8][9] [10][11].
1. Business Understanding
2. Data Understanding
3. Data Preparation
4. Modelling
5. Evaluation
6. Deployment

Metode decision tree merupakan salah satu metode yang ada pada teknik klasifikasi dalam data mining. Metode pohon keputusan mengubah fakta yang sangat besar menjadi pohon keputusan yang merepresentasikan aturan.[12] [13]Pohon keputusan juga berguna untuk mengekplorasi data, menemukan hubungan tersembunyi antara sejumlah calon variabel input dengan sebuah variabel target.Banyak algoritma yang dapat dipakai dalam pembentukan pohon keputusan, antara lain ID3, C4.5, CART [13].

Algoritma C4.5 adalah algoritma klasifikasi data dengan teknik pohon keputusan yang memiliki kelebihan-kelebihan. Kelebihan ini misalnya dapat mengolah data numerik dan diskret, dapat menangani nilai atribut yang hilang, menghasilkan aturan - aturan yang mudah diintrepetasikan dan tercepat di antara algoritma algoritma yang lain [14] untuk membangun pohon keputusan pertama yansg akan dilakukan yaitu memilih atribut sebagai akar. Kemudian membuat cabang untuk setiap nilai didalam akar tersebut. Langkah selanjutnya dengan membagi kasus dalam cabang. Kemudian ulangi proses untuk setiap cabang sampai semua kasus pada cabang memiliki kelas yang sama [14] [15][16]. Perhitungan nilai entropy yang dapat dilihat pada persamaan di bawah ini :

$$
\operatorname{Entropy}(S)=\sum_{i=1}^{n}-p i * \log _{2} p
$$

Keterangan:

$\mathrm{S}=$ Himpunan Kasus

$\mathrm{n} \quad=$ Jumlah Partisi S

Pi = Porsi dari Si terhadap S 
Gain adalah salah satu atribute selection measure yang digunakan untuk memilih test atribut tiap node pada tree. Atribut dengan information gain tertinggi dipilih sebagai test atribut dari suatu node [14][15][16] .

$$
\operatorname{Gain}(S, A)=\operatorname{Entropy}(S)-\sum_{t=i}^{n} \frac{|S i|}{|S|} * \operatorname{Entropy}(S)
$$

Keterangan:

$$
\begin{array}{ll}
\mathrm{S} & =\text { Himpunan kasus } \\
\mathrm{A} & =\text { Atribut } \\
\mathrm{n} & =\text { Jumlah partisi atribut } \mathrm{A} \\
|\mathrm{Si}| & =\text { Jumlah kasus pada partisi ke }-\mathrm{i}
\end{array}
$$

\section{METODE/PERANCANGAN PENELITIAN}

\subsection{Business Understanding}

Pada tahap pertama berfokus pada kebutuhan berdasarkan penilaian bisnis, tujuan bisnis berdasarkan pengolahan data untuk mengambil keputusan mengenai diagnosis jantung koroner. Saat ini metode yang digunakan oleh pihak rumah sakit untuk memberi keputusan klinis dibuat berdasarkan ilmu dan pengetahuan dari pasien-pasien penyakit jantung koroner.

\subsection{Data Understanding}

Tahap data understanding penulis melakukan pemahaman data dari faktor risiko penyakit jantung koroner yang terdiri dari umur, jenis kelamin, faktor keturunan, tekanan darah sistolik, tekanan darah diastolik, kadar kolesterol total, kadar HDL, kadar LDL dan kadar trigliserida. Data yang digunakan tahun 2017 sampai 2021.

Tabel 1. Data Mentah

\begin{tabular}{|r|r|r|r|r|r|r|r|r|r|r|}
\hline No & Umur & Jeniskelamin & $\begin{array}{c}\text { Tekanan } \\
\text { darah } \\
\text { sistolik }\end{array}$ & $\begin{array}{r}\text { Tekanan } \\
\text { darah } \\
\text { diastolic }\end{array}$ & $\begin{array}{c}\text { kadar } \\
\text { kolesterol } \\
\text { total }\end{array}$ & HDL & LDL & Trigliserida & $\begin{array}{c}\text { Faktor } \\
\text { keturunan }\end{array}$ & Target \\
\hline 1 & 52 & 0 & 180 & 98 & 147 & 47,4 & 76 & 263 & 1 & 1 \\
\hline 2 & 48 & 0 & 127 & 75 & 172 & 22 & 100 & 252 & 1 & 1 \\
\hline 3 & 64 & 0 & 122 & 85 & 177 & 138,2 & 25,1 & 102 & 0 & 0 \\
\hline 4 & 38 & 1 & 153 & 98 & 156 & 30 & 100 & 228 & 1 & 1 \\
\hline 5 & 64 & 1 & 128 & 82 & 163 & 75 & 37,6 & 145 & 0 & 0 \\
\hline 6 & 40 & 0 & 118 & 84 & 164 & 100 & 33 & 144 & 0 & 0 \\
\hline 7 & 75 & 1 & 130 & 70 & 272 & 45 & 177 & 248 & 0 & 0 \\
\hline 8 & 64 & 1 & 144 & 91 & 247 & 59,5 & 161 & 131 & 1 & 1 \\
\hline 9 & 46 & 0 & 127 & 81 & 128 & 65 & 49,9 & 144 & 0 & 0 \\
\hline 10 & 66 & 0 & 132 & 53 & 146 & 31,2 & 97 & 151 & 1 & 1 \\
\hline 11 & 64 & 0 & 120 & 70 & 134 & 22 & 106 & 112 & 0 & 1 \\
\hline 12 & 70 & 1 & 131 & 83 & 210 & 63 & 182 & 220 & 1 & 1 \\
\hline 13 & 67 & 1 & 200 & 120 & 121 & 226 & 24,8 & 151 & 1 & 0 \\
\hline 14 & 37 & 1 & 118 & 77 & 143 & 84,8 & 30,3 & 117 & & 0 \\
\hline 15 & 62 & 0 & 128 & 83 & 108 & 70,9 & 54 & 142 & & 0 \\
\hline 16 & 51 & 1 & 110 & 70 & 191 & 60,7 & 144 & 82 & 0 & 0 \\
\hline 17 & 8 & 1 & 127 & 75 & 22 & 150 & 240 & 210 & 1 & 1 \\
\hline 18 & 59 & 0 & 113 & 68 & 202 & 31,2 & 160 & 18 & 1 & 1 \\
\hline 19 & 46 & 1 & 153 & 79 & 186 & 61 & 131 & 78 & 0 & 1 \\
\hline 20 & 64 & 0 & 126 & 83 & 113 & 164 & 32,1 & 105 & & 0 \\
\hline
\end{tabular}




\subsection{Data Preparation}

Tahapan ini seluruh data dilakukan klasifikasi ke dalam kelas- kelas tertentu pada setiap atribut agar dapat diolah dengan algoritma C4.5.

Tabel 2. Data Klasifikasi

\begin{tabular}{|r|r|l|l|l|l|l|l|l|r|l|}
\hline No Umur & Jeniskelamin & $\begin{array}{c}\text { Tekanan } \\
\text { darah } \\
\text { sistolik }\end{array}$ & $\begin{array}{c}\text { Tekanan } \\
\text { darah } \\
\text { diastolik }\end{array}$ & $\begin{array}{c}\text { kadar } \\
\text { kolesterol } \\
\text { total }\end{array}$ & HDL & LDL & Trigliserida & $\begin{array}{c}\text { Faktor } \\
\text { keturunan }\end{array}$ & Target \\
\hline 1 & 3 & $\mathrm{P}$ & $\mathrm{HB}$ & $\mathrm{HR}$ & $\mathrm{N}$ & $\mathrm{S}$ & $\mathrm{MO}$ & $\mathrm{T}$ & 1 & YA \\
\hline 2 & 2 & $\mathrm{P}$ & $\mathrm{NT}$ & $\mathrm{N}$ & $\mathrm{N}$ & $\mathrm{R}$ & $\mathrm{MO}$ & $\mathrm{T}$ & 1 & YA \\
\hline 3 & 3 & $\mathrm{P}$ & $\mathrm{NT}$ & $\mathrm{NT}$ & $\mathrm{N}$ & $\mathrm{T}$ & $\mathrm{O}$ & $\mathrm{N}$ & 0 & TIDAK \\
\hline 4 & 2 & $\mathrm{~L}$ & $\mathrm{HR}$ & $\mathrm{HR}$ & $\mathrm{N}$ & $\mathrm{R}$ & $\mathrm{MO}$ & $\mathrm{T}$ & 1 & YA \\
\hline 5 & 3 & $\mathrm{~L}$ & $\mathrm{NT}$ & $\mathrm{NT}$ & $\mathrm{N}$ & $\mathrm{T}$ & $\mathrm{O}$ & $\mathrm{N}$ & 0 & TIDAK \\
\hline 6 & 2 & $\mathrm{P}$ & $\mathrm{N}$ & $\mathrm{NT}$ & $\mathrm{N}$ & $\mathrm{T}$ & $\mathrm{O}$ & $\mathrm{N}$ & 0 & TIDAK \\
\hline 7 & 5 & $\mathrm{~L}$ & $\mathrm{NT}$ & $\mathrm{N}$ & $\mathrm{T}$ & $\mathrm{S}$ & $\mathrm{T}$ & $\mathrm{T}$ & 0 & TIDAK \\
\hline 8 & 3 & $\mathrm{~L}$ & $\mathrm{HR}$ & $\mathrm{HR}$ & $\mathrm{T}$ & $\mathrm{S}$ & $\mathrm{O}$ & $\mathrm{N}$ & 1 & YA \\
\hline 9 & 2 & $\mathrm{P}$ & $\mathrm{NT}$ & $\mathrm{NT}$ & $\mathrm{N}$ & $\mathrm{T}$ & $\mathrm{O}$ & $\mathrm{N}$ & 0 & TIDAK \\
\hline 10 & 4 & $\mathrm{P}$ & $\mathrm{NT}$ & $\mathrm{N}$ & $\mathrm{N}$ & $\mathrm{R}$ & $\mathrm{O}$ & $\mathrm{BT}$ & 1 & YA \\
\hline 11 & 4 & $\mathrm{P}$ & $\mathrm{NT}$ & $\mathrm{N}$ & $\mathrm{N}$ & $\mathrm{S}$ & $\mathrm{O}$ & $\mathrm{T}$ & 1 & YA \\
\hline 12 & 4 & $\mathrm{~L}$ & $\mathrm{NT}$ & $\mathrm{NT}$ & $\mathrm{BT}$ & $\mathrm{T}$ & $\mathrm{T}$ & $\mathrm{T}$ & 1 & YA \\
\hline 13 & 4 & $\mathrm{~L}$ & $\mathrm{HB}$ & $\mathrm{HB}$ & $\mathrm{N}$ & $\mathrm{T}$ & $\mathrm{O}$ & $\mathrm{BT}$ & 1 & TIDAK \\
\hline 14 & 2 & $\mathrm{~L}$ & $\mathrm{~N}$ & $\mathrm{~N}$ & $\mathrm{~N}$ & $\mathrm{~T}$ & $\mathrm{O}$ & $\mathrm{N}$ & 0 & TIDAK \\
\hline 15 & 3 & $\mathrm{P}$ & $\mathrm{NT}$ & $\mathrm{NT}$ & $\mathrm{N}$ & $\mathrm{T}$ & $\mathrm{O}$ & $\mathrm{N}$ & 0 & TIDAK \\
\hline 16 & 3 & $\mathrm{~L}$ & $\mathrm{~N}$ & $\mathrm{~N}$ & $\mathrm{~N}$ & $\mathrm{~T}$ & $\mathrm{BT}$ & $\mathrm{N}$ & 0 & TIDAK \\
\hline 17 & 1 & $\mathrm{~L}$ & $\mathrm{NT}$ & $\mathrm{N}$ & $\mathrm{N}$ & $\mathrm{T}$ & $\mathrm{ST}$ & $\mathrm{T}$ & 1 & YA \\
\hline 18 & 2 & $\mathrm{P}$ & $\mathrm{HR}$ & $\mathrm{NT}$ & $\mathrm{N}$ & $\mathrm{S}$ & $\mathrm{O}$ & $\mathrm{T}$ & 1 & YA \\
\hline 19 & 2 & $\mathrm{~L}$ & $\mathrm{HR}$ & $\mathrm{N}$ & $\mathrm{N}$ & $\mathrm{T}$ & $\mathrm{BT}$ & $\mathrm{N}$ & 0 & YA \\
\hline 20 & 3 & $\mathrm{P}$ & $\mathrm{NT}$ & $\mathrm{NT}$ & $\mathrm{N}$ & $\mathrm{T}$ & $\mathrm{O}$ & $\mathrm{N}$ & TIDAK \\
\hline
\end{tabular}

\subsection{Modeling}

Pada tahap pemodelan data yang sudah di klasifikasi, kemudian diproses menggunakan metodedata mining yaitu algoritma C4.5. Berikut langkah-langkah perhitungan entrophy dan gain pada setiap atribut :

1. Perhitungan nilai entrophy

Langkah pertama dalam perhitungan algoritma $\mathrm{C} 4.5$ yaitu mencari niIai entrophy. Rumus mencari entrophy sebagai berikut:

$\operatorname{Entropy}(S)=\sum_{i=1}^{n}-p i * \log _{2} p i$

Entrophy total $(\mathrm{S})=(-($ jumlah target ya/total target $) * \log 2($ jumlah target ya/total target $))+$ (-(jumlah target tidak/total target) *log2(jumlah target tidak/total target))

a) Entrophy total

$$
\begin{aligned}
& =(-(10 / 20) * \log 2(10 / 20))+(-(10 / 20) * \log 2(10 / 20)) \\
& =1
\end{aligned}
$$

b) Entrophy umur

$=(-(4 / 7) * \log 2(4 / 7))+(-(3 / 7) * \log 2(3 / 7))$

$=0,985$ 
2. Perhitungan nilai gain

Setelah selesai melakukan perhitungan entrophy pada masing-masing subset atribut, dilakukannya perhitungan gain untuk memilih atribut yang digunakan sebagai akar dengan nilai gain tertinggi dengan rumus:

$\operatorname{Gain}(S, A)=\operatorname{Entropy}(S)-\sum_{t=i}^{n} \frac{|S i|}{|S|} * \operatorname{Entropy}(S)$

Gain $=$ Entrophy total $-($ target $/$ total target $*$ Entrophy target $)$

a) Gain umur

$=1-(1 / 20 * 0)+(7 / 20 * 0,985)+(7 / 20 * 0,863)+(4 / 20 * 0,811)+(1 / 20 * 0)$

$=0,191$

b) Gain Faktor keturunan

$=1-(10 / 20 * 0,469)+(10 / 20 * 0,469)$

$=0,531$

3. Ulangi Langkah perhitungan entrophy dan gain ke semua atribut hingga mendaptakan hasil seperti table 3 Dari hasil tabel maka didapatkan nilai gain tertinggi yaitu faktor keturunan sebagai akar pertama, untuk akar berikutnya maka dilakukan perhitungan untuk entrophy dan gain pada atribut selanjutnya.

Tabel 3. Hasil Perhitungan Nilai Entrophy dan Gain

\begin{tabular}{|c|c|c|c|c|c|c|}
\hline & & $\begin{array}{c}\text { JUMLAH } \\
(\mathrm{S})\end{array}$ & $\mathrm{YA}(\mathrm{Si})$ & $\begin{array}{l}\text { TIDAK } \\
(\mathrm{Si})\end{array}$ & ENTROPHY & GAIN \\
\hline TOTAL & & 20 & 10 & 10 & 1 & \\
\hline \multirow{6}{*}{ UMUR } & & & & & & 0,191 \\
\hline & 1 & 1 & 1 & 0 & 0 & \\
\hline & 2 & 7 & 4 & 3 & 0,985 & \\
\hline & 3 & 7 & 2 & 5 & 0,863 & \\
\hline & 4 & 4 & 3 & 1 & 0,811 & \\
\hline & 5 & 1 & 0 & 1 & 0 & \\
\hline \multirow{3}{*}{$\begin{array}{c}\text { JENIS } \\
\text { KELAMIN }\end{array}$} & & & & & & 0 \\
\hline & $\mathrm{L}$ & 10 & 5 & 5 & 1 & \\
\hline & $\mathrm{P}$ & 10 & 5 & 5 & 1 & \\
\hline \multirow{6}{*}{$\begin{array}{c}\text { TEKANAN } \\
\text { DARAH } \\
\text { SISTOLIK }\end{array}$} & & & & & & 0,353 \\
\hline & $\mathrm{N}$ & 3 & 0 & 3 & 0 & \\
\hline & NT & 11 & 5 & 6 & 0,994 & \\
\hline & HR & 4 & 4 & 0 & 0 & \\
\hline & HS & 0 & 0 & 0 & 0 & \\
\hline & HB & 2 & 1 & 1 & 1 & \\
\hline \multirow{6}{*}{$\begin{array}{l}\text { TEKANAN } \\
\text { DARAH } \\
\text { DIASTOLIK }\end{array}$} & & & & & & 0,294 \\
\hline & $\mathrm{N}$ & 8 & 5 & 3 & 0,954 & \\
\hline & NT & 8 & 2 & 6 & 0,811 & \\
\hline & HR & 3 & 3 & 0 & 0 & \\
\hline & HS & 0 & 0 & 0 & 0 & \\
\hline & HB & 1 & 0 & 1 & 0 & \\
\hline
\end{tabular}




\begin{tabular}{|c|c|c|c|c|c|c|}
\hline \multirow{4}{*}{$\begin{array}{c}\text { KADAR } \\
\text { KOLESTEROL } \\
\text { TOTAL }\end{array}$} & & & & & & 0,052 \\
\hline & $\mathrm{N}$ & 17 & 8 & 9 & 0,998 & \\
\hline & BT & 1 & 1 & 0 & 0 & \\
\hline & $\mathrm{T}$ & 2 & 1 & 1 & 1 & \\
\hline \multirow{4}{*}{ HDL } & & & & & & 0,333 \\
\hline & $\mathrm{R}$ & 3 & 3 & 0 & 0 & \\
\hline & $\mathrm{S}$ & 5 & 4 & 1 & 0,722 & \\
\hline & $\mathrm{T}$ & 12 & 3 & 9 & 0,811 & \\
\hline \multirow{6}{*}{ LDL } & & & & & & 0,249 \\
\hline & $\mathrm{O}$ & 12 & 4 & 8 & 0,918 & \\
\hline & MO & 3 & 3 & 0 & 0 & \\
\hline & BT & 2 & 1 & 1 & 1 & \\
\hline & $\mathrm{T}$ & 2 & 1 & 1 & 1 & \\
\hline & ST & 1 & 1 & 0 & 0 & \\
\hline \multirow{5}{*}{ TRIGLISERIDA } & & & & & & 0,322 \\
\hline & $\mathrm{N}$ & 10 & 2 & 8 & 0,722 & \\
\hline & BT & 2 & 1 & 1 & 1 & \\
\hline & $\mathrm{T}$ & 8 & 7 & 1 & 0,544 & \\
\hline & ST & 0 & 0 & 0 & 0 & \\
\hline \multirow{3}{*}{$\begin{array}{c}\text { FAKTOR } \\
\text { KETURUNAN }\end{array}$} & & & & & & 0,531 \\
\hline & 1 & 10 & 9 & 1 & 0,469 & \\
\hline & 0 & 10 & 1 & 9 & 0,469 & \\
\hline
\end{tabular}

\subsection{Evaluation}

Tahap evaluasi merupakan hasil dari data mining, dapat disimpulkan berdasarkan pohon keputusan yang dihasilkan. Pada pengujian hasil akurasi menggunakan metode confussion matrix.

\subsection{Deployment}

Pada tahap ini penulis melakukan penyusunan laporan dari proses yang telah dilakukan, untuk penyajian hasil ditampilkan dengan tampilan yang mudah dipahami agar dapat diimplemantasikan.

\section{HASIL DAN PEMBAHASAN}

Data yang digunakan 300 data berisi variabel umur, jenis kelamin, tekanan darah sistolik, tekanan darah diastolik, kadar kolesterol total, kadar HDL, kadar LDL, kadar trigliserida, dan faktor keturunan, Kemudian di implementasikan menggunakan metode decision tree. data akan diolah menjadi data pelatihan. dan data pengujian.

Data pelatihan digunakan untuk membuat pohon keputusan di dalam sistem. Pohon keputusan digunakan sebagai acuan untuk menetukan apakah seseorang berdasar data yang digunakan terdiagnosis jantung koroner atau tidak. Berdasarkan hasil 110 data latih yang digunakan maka menghasilkan sebuah pohon keputusan seperti gambar 1 

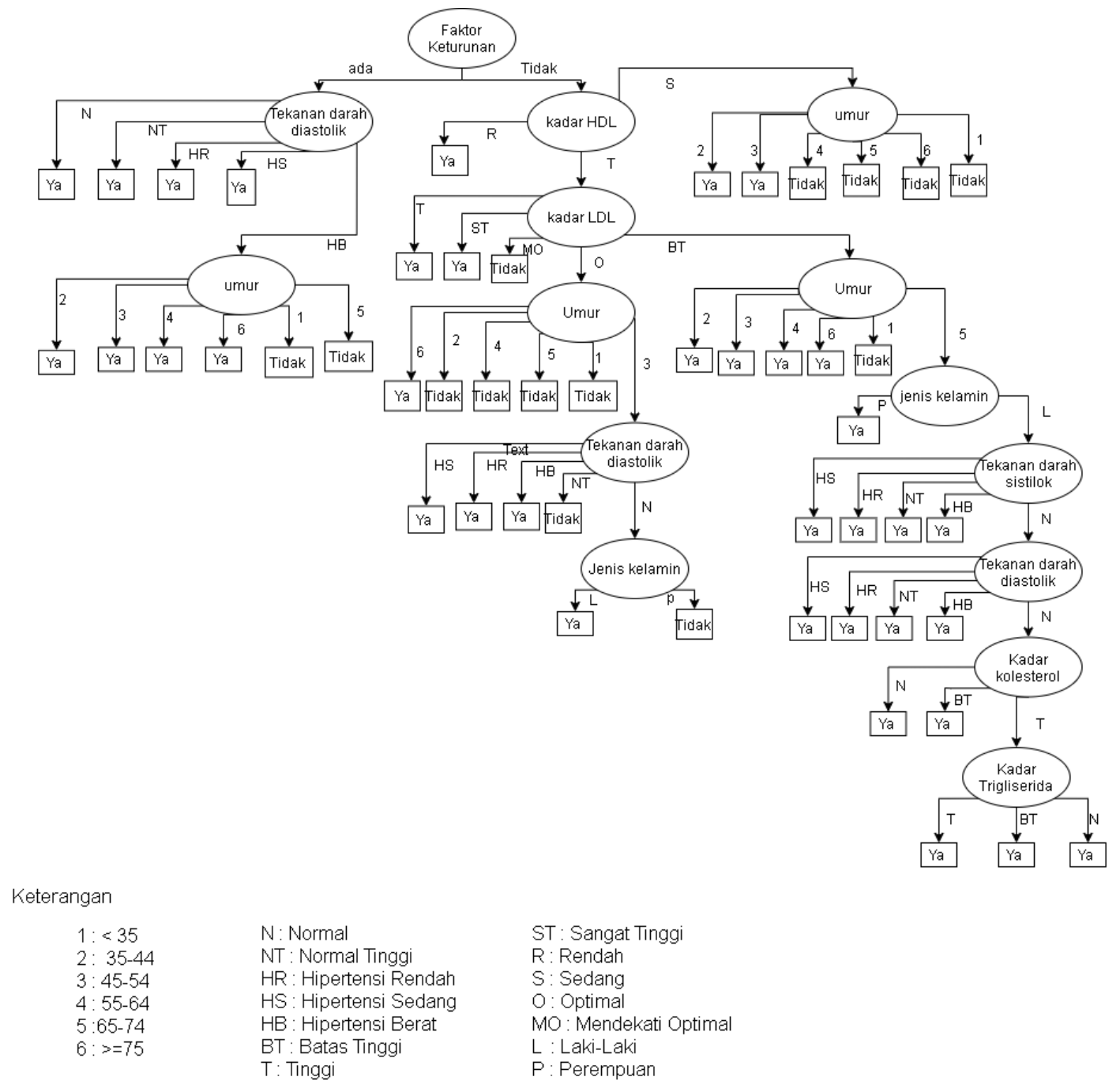

Gambar 1. Pohon Keputusan

Data pengujian digunakan untuk mengetahui keakuratan dari hasil klasifikasi diukur dengan menggunakan confusion matrix, [17] Dimana data hasil prediksi berada diantara dua kelas yaitu kelas positif dan kelas negatif. Pengukuran digunakan adalah pengukuran akurasi. Berikut tabel confusion matrix dengan jumlah data uji 90 data dari hasil data pengujian menghasilkan data 85 data teridentifikasi benar dan 5 data teridentifikasi salah.

Tabel 4. Confusion Matrix

\begin{tabular}{|l|l|l|}
\hline \multirow{2}{*}{ actual } & \multicolumn{2}{|c|}{ Prediksi } \\
\cline { 2 - 3 } & kelas = ya & kelas = tidak \\
\hline kelas = ya & TP (True Positive) & FP (False Positive) \\
& 68 & 3 \\
\hline kelas = tidak & FN (False Negative) & TN (True Negative) \\
& 2 & 17 \\
\hline
\end{tabular}

Perhitungan akurasi dilakukan dengan membagi jumlah data yang diklasifikasikan secara benar dengan total data sampel yang diuji. Rumus dari akurasi yaitu: 


$$
\text { akurasi }=\frac{T P+T N}{T P+T N+F P+F N}
$$

$$
\begin{aligned}
& \text { Keterangan: } \\
& \mathrm{TP}=68 \\
& \mathrm{TN}=17 \\
& \mathrm{FP}=2 \\
& \mathrm{FN}=3 \\
& \text { akurasi }=\frac{68+17}{68+17+2+3} \\
& \text { akurasi }=\frac{85}{90} \\
& \text { akurasi }=0,944 \times 100 \% \\
& \text { akurasi }=94,4 \%
\end{aligned}
$$

Berdasarkan hasil akurasi yang dilakuakan didapatlah dengan hasil akurasi sebesar 94,4\% dengan metode decision tree, maka penelitian ini menerapkan metode decision tree algoritma $\mathrm{C} 4.5$ pada kasus diagnosis jantung coroner.

\section{KESIMPULAN DAN SARAN}

\subsection{Kesimpulan}

Dari hasil penelitian yang sudah dilakukan, kesimpulan yang dapat diambil adalah Algoritma C4.5 untuk diagnosis penyakit jantung koroner dapat diimplementasikan dengan baik dengan pengujian perbandingan data latih dan data uji sebesar $70: 30$ dan menghasilkan akurasi sebesar $94,4 \%$

\subsection{Saran}

Adapun saran yang dibuthkan agar penelitian ini dapat berkembang diantara lain:

1. Program dapat mengimport data selain data bertipe.csv.

2. Pada pengembangan penelitian selanjutnya dapat dikembangan dengan menggunakan algoritma elman recurrent neural network (ERNN).

3. Menambah jumlah data untuk memperbaiki hasil dari proses pelatihan

\section{UCAPAN TERIMAKASIH}

Ucapan terima kasih sebesar-besarnya saya ucapkan kepada RSUD Dr. Soedarso Pontianak dan Institut Teknologi PLN kesempatan untuk melakukan penelitian ini.

\section{DAFTAR PUSTAKA}

[1] V. M. Tarawan, R. Lesmana, H. Gunawan, and J. windi Gunandi, "GAMBARAN PENGETAHUAN PENCEGAHAN PENYAKIT JANTUNG KORONER PADA WARGA DUSUN III DESA MEKARMANIK KECAMATAN CIMENYAN KABUPATEN BANDUNG," vol. 4, no. 1, pp. 10-14, 2020.

[2] W. G. Amisi, jeini E. Nelwan, and F. k Kolibu, "HUBUNGAN ANTARA HIPERTENSI DENGAN KEJADIAN PENYAKIT JANTUNG KORONER PADA PASIEN YANG BEROBAT DI RUMAH SAKIT UMUM PUSAT Prof. Dr. R. D. KANDOU MANADO Windy," vol. 7.

[3] K. Noviyanti and E. K. S. L, "Hubungan profil lipid dan C-reactive protein ( CRP ) dengan derajat stenosis koroner pada penyakit jantung koroner stabil," vol. 10, no. 1, pp. 165-168, 
2019, doi: 10.1556/ism.v10i1.332.

[4] L. Ghani, M. D. Susilawati, and H. Novriani, "Faktor Risiko Dominan Penyakit Jantung Koroner di Indonesia," Bul. Penelit. Kesehat., vol. 44, no. 3, pp. 153-164, 2016, doi: 10.22435/bpk.v44i3.5436.153-164.

[5] L. A. Larandipa, F. T. P. W, D. Triyanto, P. Jantung, F. Resiko, and J. S. Tiruan, "APLIKASI JARINGAN SYARAF TIRUAN UNTUK DIAGNOSA PENYAKIT JANTUNG KORONER ( PJK ) DENGAN METODE BACKPROPAGATION Skripsi ini dibahas aplikasi Jaringan Syaraf Tiruan ( JST ) untuk diagnosa Penyakit Jantung Koroner ( PJK ) dengan metode backpropagation . Aplik," vol. 01, no. 1, 2013.

[6] N. Effendy and A. Faisal, "PREDIKSI PENYAKIT JANTUNG KORONER ( PJK ) BERDASARKAN FAKTOR RISIKO MENGGUNAKAN JARINGAN SYARAF TIRUAN BACKPROPAGATION," vol. 2008, no. Snati, 2008.

[7] S. Masripah, "Komparasi Algoritma Klasifikasi Data Mining untuk Evaluasi Pemberian Kredit," vol. 3, no. 1, pp. 187-193, 2016.

[8] A. Asistyasari, "PENCARIAN PRODUK E-COMMERCE BERDASARKAN JUDUL DAN DESKRIPSI MENGGUNAKAN VECTOR SPACE MODEL,” pp. 53-58, 2020.

[9] U. Pauziah, "ANALISIS PENENTUAN KARYAWAN TERBAIK MENGGUNAKAN METODE ALGORITMA NAIVE BAYES ( STUDI KASUS PT . XYZ),” no. April, pp. 94$102,2017$.

[10] N. Nuraeni, "Penentuan Kelayakan Kredit Dengan Algoritma Naïve Bayes Classifier : Studi Kasus Bank Mayapada Mitra Usaha Cabang PGC,” vol. III, no. 1, pp. 9-15, 2017.

[11] F. Nurhassan, N. Hikmah, and D. Y. Utami, "Perbandingan algoritma c4.5, knn, dan naive bayes untuk penentuan model klasifikasi penanggung jawab bsi entrepreneur center," vol. 14, no. 2, pp. 169-174, 2018.

[12] S. Wahyuni, kana S. S, and M. I. Perangin-angin, "IMPLEMENTASI RAPIDMINER DALAM MENGANALISA DATA MAHASISWA DROP OUT," vol. 10, pp. 2013-2016, 2017.

[13] F. Dwi Meliani Achmad, Budanis, Slamat, "Klasifikasi Data Karyawan Untuk Menentukan Jadwal Kerja Menggunakan Metode Decision Tree," J. IPTEK, vol. 16, no. 1, pp. 18-23, 2012, [Online]. Available: http://jurnal.itats.ac.id/wp-content/uploads/2013/06/3.-BUDANISFINAL-hal-17-23.pdf.

[14] A. Sonita and R. Kundari, "APLIKASI SELEKSI CALON PENDONOR," vol. VI, no. September, 2019.

[15] L. Hermawanti, "Penerapan algoritma klasifikasi c4.5 untuk diagnosis penyakit kanker payudara," vol. 7, no. 1, pp. 57-64, 2012.

[16] B. Sugara, D. Widyatmoko, B. S. Prakoso, and D. M. Saputro, "Penerapan Algoritma C4.5 untuk Deteksi Dini Autisme Pada Anak," Semin. Nas. Teknol. Inf. dan Komun., vol. 2018, no. Sentika, pp. 87-96, 2018.

[17] D. Hanifah, C. Prianto, and N. Riza, Buku laporan rancang bangun aplikasi pengambilan keputusan dalam pemilihan karyawan pada kegiatan akademik perusahaan dengan menggunakan perbandingan metode topsis dan metode promethee. 2020. 